\title{
Chores, Incubator for a Strong Parent-Child Relationship
}

\author{
Shi Li \\ School of Arts, University of New England, Australia
}

Copyright $(2016$ by authors, all rights reserved. Authors agree that this article remains permanently open access under the terms of the Creative Commons Attribution License 4.0 International License

\begin{abstract}
Based on the latest finding of a longitudinal study that sons-in-law (under the influence of their wives) performed better in affective care to their parents-in-law than daughters-in-law, this article argues that it is perhaps not gender but housework that holds the key for a strong parent-child relationship. This article posits that, through engaging children in routine chores, social justice will be internalised or habitualised in children, which then enables parental love to be reciprocated with children's love. This article theoretically discusses the mechanism for gratitude development towards parents in children and suggests that chores may play a vital role in gratitude development in children, which leads to a strong parent-child bond.
\end{abstract}

Keywords Gratitude, Chores, Morality of Justice, Parental Love, Induction, Moral Reasoning, Discipline, Filial Piety, One-child Generations

\section{Introduction}

Research found that today young people are more self-centred than ever worldwide [1-5], whose sense of duty, obligation and responsibility to or care for others has given way to unbounded narcissism in an over-entitled world [6-8]. This is not of particular concern in China that the one-child policy has created the self-centred young generation [9-11], but also in developed countries such as America [2, 4, 5, 12, 13]. Nowadays increasing longevity and the growing expectation that older citizens are better supported in their homes for as long as possible has created tension between the practical and emotional support needs of older citizens, and the willingness of adult children to supply those supports worldwide [14-16]. This is all the more so for countries such as China, where state provides limited support for older citizens; rather there are legal and moral expectations adult children will support elderly parents, financially, practically and emotionally [17-19].The issue of egocentrism in young generations not only has a significant negative impact on the physical and psychological wellbeing of young individuals [20-23], but also on the relationship with their parents, subsequently on the physical and mental wellbeing of these parents in old age.
Enlightened by the new findings of the Chinese Longitudinal Healthy Longevity Survey (CLHLS) [24], this article is to theoretically explore a way of fostering a parent-child relationship by discussing the role of chores in gratitude development towards parents in children or in the development of a strong parent-child bond. In this article, the CLHLS findings are first introduced with the demographic description of its participants. Then a review on the literature of the basic types of and the development model of the parent-child relationship is conducted. After that, a mechanism for gratitude development in children, morality of justice, is elucidated on three interrelated and integrated dimensions: parental love, induction and discipline. Finally, chores are theoretically discussed as a critical active disciplinary measure in transforming moral knowledge into moral actions through internalising social justice in children, and in such a way that parental love can be translated into the reciprocity of children's love and a strong parent-child bond can be developed.

\section{The Chinese Longitudinal Healthy Longevity Survey (CLHLS)}

The CLHLS was a seven-year nation-wide follow-up investigation, conducted by the Center for Healthy Aging and Family Studies and the China Center for Economic Research, Beijing University, which paid door-to-door visits to elderly families in 22 provinces of China up to 60,000 times in total in 1998, 2000, 2002 and 2005. The CLHLS findings were released by Beijing University were released in November 2015, which suggested that raising a daughter yields a much better return than a son for old parents in need of affective care in China. This is especially the case in the rural areas where, ironically, a traditional ideology of boys being more valued than girls still prevails. The results of their data analysis showed that:

- the filial piety sense indices ${ }^{1}$ for an adult daughter

\footnotetext{
1 The filial piety sense index refers to a composite index that is based on an evaluation of responses to nine questions on whether and how an adult child of 35 or older should perform their filial duty. The survey was conducted on 4364 elderly parents randomly selected. Scores ranged from 9 to 45 .
} 
were higher than those for an adult son by $35 \%$ in rural areas and $18 \%$ in urban areas;

- the affective bond of old parents with an adult daughter was significantly stronger than with an adult son by up to $28-29 \%$;

- satisfaction with a daughter acting as a principal daily carer (including when parents are ill) was higher than with a son by $45 \%$, while satisfaction with a son-in-law was higher than a daughter-in-law by $13 \%$;

- risk of decrease in the cognitive ability of old populations who were more in communication with a daughter and a son-in-law was lower than those who were more in communication with a son and a daughter-in-law by $33 \%$ in rural areas and $16 \%$ in urban areas;

- risk of death for old parents, in both rural and urban areas, who only had one daughter was lower than those who only had one son by $25 \%$ in rural areas and $10 \%$ in urban areas for the observation period of seven years from 1998 to 2005 . The death rate of parents in their advanced old age who only had one daughter, compared to those who only had one son was lower $(18 \%)$ and it was also lower in their middle and early old age (6\%). Even risk of death for parents, in both rural and urban areas, who only had one daughter was lower than those having both a daughter and a son by $25 \%$ and $13 \%$, respectively.

The results confirm the findings by Ho [25] that adult Chinese daughters practised filial piety more than did adult Chinese sons in both Hong Kong and Taiwan. However, a unique finding from the CLHLS is noteworthy - sons-in-law perform better than daughters-in-law in providing daily care and affective comfort for their parents-in-law. The investigators of the CLHLS attributed all these results to different gender roles in a family with an adult son being responsible for financial support and an adult daughter providing daily care and affective comfort; yet they manifestly failed to give a good reason as to why a son-in-law, as a male, performed better than a daughter-in-law, as a female, in providing daily care and affective comfort. In fact, the reason is simple. The son-in-law performed better due to the influence of his wife, the daughter. Yet, this appears to proclaim that an adult man can provide better affective care to old parents than an adult woman. This inference makes untenable the classical view that difference in gender is the cause of the bond between old parents and an adult daughter being stronger than between old parents and an adult son. Given the fact that chores are customarily considered as a major construct to distinguish the family roles of a daughter and a son [25-27], could it be that chores play a critical role in the development of a stronger bond between parents and an adult daughter?

A strong bond between an adult child and old parents is important for the physical and mental health of old parents and for addressing the global issue of an ageing population in a broad sense [28-30]. Therefore, it is important and indeed imperative to explore the role that chores play in the development of a strong bond between children and parents in childhood - a critical phase for the development of children's affection for their parents.

It is necessary at the very beginning of the discussion to clear up a possible misconception that the children participating in the CLHLS could be of the one-child generations of China, which resulted from the notorious one-child policy $[9,11,31]$. The participating adult children in the CLHLS between 1998 and 2005 were almost all from multi-child families, not Chinese one-child generations. The one-child policy was put in place in 1979 and by the start of the CLHLS in 1998, the oldest children, born in 1980, would have reached 18 years of age, and by the last year of investigation in 2005, would have turned 25. All the old parents participating in the investigations between 1998 and 2005 were over 65 years of age, and their adult children were 35 or older and would have been born in the 1950s, 1960s and early $1970 \mathrm{~s}$ - obviously not of the one-child generations. These adult children were mostly brought up in a multi-child family, in which they had to share household chores and look after their siblings. What was a feature of these traditional Chinese families was that a son was valued and prioritised for education, while a daughter was required to perform some, if not all, the routine chores [32,33]. Besides the very harsh lives that these children experienced before the reform, perhaps what made them uniquely distinctive from children in other countries was their encounter with the Cultural Revolution (1966-1976) during their schooling years. This political turmoil advocated "study is useless", which left most of these children much less educated through their lifetimes, compared to younger Chinese generations. Yet, the harsh lives also inspired and developed in most of them the ethos of working hard, independence, fortitude and sacrifice [34].

\section{Three Major Theories on the Parent- child Relationship}

A literature review on a parent-child relationship reveals three major theories, the debt theory, the gratitude theory and the friendship theory [35]. The debt theory holds that children are in debt to their parents for being conceived, born, fed, clad, and taken care of. A child is like someone who has taken out a loan from his or her parents and has to discharge it, yet there is no way of determining the magnitude of this debt nor when the debt, in the form of filial duties, has been discharged once and for all [35-37]. However, it can be argued that caring for a child is the parents' obligation by virtue of having brought the child into existence. More importantly, the concept of a debt to be repaid bears the connotations of a business transaction that undermines the moral motivation of parental sacrifices if parents place open-ended and demanding duties upon their children. Thus, in nature, the debt theory poses a moral dilemma [19, 31, 37]. 
The friendship theory views a parent-child relationship as friendship between friends, and the duties between adult children and their parents as the duties of friends [37]. What is noteworthy is that filial duty only lies "in the relationship shared by children and parents in the present" [35]. According to the friendship theory, filial duties do not depend on the extent of parental sacrifices involved in raising a child in the past but the friendship currently sustained between children and parents. Therefore, children only contribute to their parents what they reasonably can, and this should not impede their autonomy or ability to live a good life [37, 38]. However, it can also be argued that a parent-child relationship is not a matter of ongoing choice on a voluntary basis as friendship is. And the magnitude of filial duties is completely different from that of duties to friends. For example, "a child who makes sacrifices to pay for a parent's care is doing something that is praiseworthy, but expected in the circumstances. Someone who makes sacrifices to pay the medical bills of a friend is doing something that is truly and unusually generous" [35]. Therefore, the friendship theory does not capture the uniqueness of a parent-child relationship.

The gratitude theory says that to fulfil one's filial duties is to perform appropriate acts of gratitude in response to the good things provided by parents; and the contents of gratitude to parents are heavily dependent upon circumstances or what a child reasonably can provide [35]. The gratitude theory involves three key dimensions. First, the extent of gratitude should depend upon how much discomfort, exertion and sacrifice is involved in parenting the child. The bottom line is whether there exists parental love that enables parents to endure discomfort, put forth effort and make sacrifices. A few studies on parental education have suggested that a good proportion of parents are neglectful; in other words, not all parents love their children [31, 39]. If parents do not love their children, then children's gratitude will lose the foundation of its existence. Second, gratitude should not be an obligation that parents should expect from their children for their early sacrifices. For example, if a parent requires his or her children to be grateful for his or her sacrifices in bringing them up, it will throw his or her initial alleged benevolence into a debt for children, then a parent-child relationship will become a business transaction. Third, filial piety should be reflected by the effort that a child puts in to providing an act of gratitude or the sincerity with which it is offered [35]. It is like the Confucian saying, “Lun Xin Bu Lun Ji" (论心不论迹), which means "it is not deed but efforts that matter" or else there will be no filial children in poor families. In sum, parents bestowing parental love merit gratitude from their children, and children, in return, should engage in acts of gratitude towards their parents to the best of their capacity. This article is primarily concerned with the gratitude theory.

\section{Literature in the Model of Developing a Parent-child Bond}

The development model of a strong parent-child bond is a two-way process of interaction between parents loving their children and the children expressing gratitude in word and/or in deed for their parental love. The parent-child bond should consist of two components. First, parental love is the prerequisite for a strong parent-child bond as the unique feature of a family. As stated above, prior studies [e.g. 31, 39] have suggested that the claim "all good is of parents" or "all parents love their child" is not true. Of 4018 American families surveyed in the $1980 \mathrm{~s}, 37.3 \%$ parents were surprisingly found to be neglectful of their children [39]. This type of parents, according to Maccoby, Martin and Hetherington [40], provides only the basic needs of food and shelter, and is emotionally disengaged in their child's life with little if any expression of love and affection. Given the fact that parents play a dominating and decisive role in a parent-child relationship during child development, there will be little possibility for the development of a strong parent-child bond if there is no parental love. Second, children express gratitude for parental love in word and/or deed. Yet, meeting the prerequisite of parental love does not mean the natural occurrence of a good parent-child relationship. A good number of empirical studies in China [41-45] found that parental love does not naturally lead to the reciprocity of children's love in its one-child generations. Their investigations revealed that some of these one-child generations took parental love for granted and even held that their parents owed them, which, while breaking the hearts of the dedicated parents, also strained the parent-child relationship. In fact, egocentrism is not of particular concern in China, but a worldwide issue [4, 5]. Twenge and Campbell [13] propose that one of the best ways to combat egocentrism is to develop gratitude in children. Therefore, scientific parenting, particularly in terms of transforming parental love into children's gratitude, becomes indispensably important for forging a strong bond between parents and children. What then has prior research said about developing a grateful child?

Gratitude is generally considered as a sense of appreciation for kindness received. A review of the literature shows two contrasting views on gratitude: an emotion as an episodic disposition in nature [e.g. 46, 47], or a personality trait as a long-term disposition [e.g. 23, 48, 49, 50]. Robert Emmons argued that "[o]ne can be prone to experiencing and certainly expressing gratitude on appropriate occasions without necessarily being a grateful person" [20]. It is true that, unlike the expression of a momentary emotion of "thanks" to someone opening a door for you, only performing consistent and ongoing acts of gratitude can be a quality of one's personality, such as regular visits to an old parent. The quality of gratitude in one's adult life can bring out a variety of benefits in terms of physical, mental and 
social wellbeing, as revealed in the aforementioned studies. Of very few researchers on gratitude development in children, Froh and Bono, in their pioneering work, Making grateful kids, suggested that "benefits of gratitude help children develop into autonomous, sociably competent, and purposeful individuals who are satisfied with their life" [51]. They hold that "some people are inherently more or less grateful than others, we were convinced that, regardless of where you fall on the gratitude meter, gratitude could be improved because it's expandable" [51]. They also developed a series of strategies for making grateful kids, such as counting one's blessings, regulating negative emotions, keeping a gratitude journal, and for parents being a gratitude role model.

Despite a blazed trail left by prior research into gratitude in child development, there are three barely unnoticeable gaps that need to be filled. First, gratitude as a quality of one's personality can diminish and even vanish in childhood without scientific parenting. The existing research acknowledges the inherency of individual discrepancy in gratitude and sees gratitude as a quality that can be improved through learning, but fails to observe that the quality of gratitude in children can also deteriorate over time under bad parenting. This has been empirically evidenced by a widespread lack of gratitude in China's one-child generations, as mentioned above. Second, all the aforementioned research on gratitude has only focused on the egoistic benefits of individuals rather than altruistic motives, while the latter is required for children to express their gratitude to their old parents in a substantial way, such as time, energy and even finance. Understandably, there are cultural differences between the West and the East in the parent-child relationship. For example, old parents in the West are more independent and prone to live independently as long as they are physically able, while old parents in the East tend to live with their child and even grandchild to enjoy the happiness of a family union. Nevertheless, in the West some substantial sacrifices are also expected such as paying regular visits, caring for an old parent when bedridden for a few days, and even paying for a parent's medical bill. Therefore, children, either in the East or in the West, need to be trained or cultivated to make sacrifices. And gratitude development in children solely centred on egoistic wellbeing can be problematic. Third, grateful acts have been overlooked in the existing research on gratitude, which gives an impression that one would be more grateful if one said one experienced gratitude more intensely, more frequently, to a wider variety of people, and across a wider span of experiences. It is true that someone who expressed their gratitude would be more likely to be a grateful person than someone who did not. However, as an old saying has it that everything is easier said than done, some people might not be as good as their word, especially when facing high costs such sacrifices in time, energy, and finance in looking after old parents. Such grateful acts have to be manifested in deed or acts that defy the hedonistic and self-interested human nature. Thus, to perform such grateful acts, human nature must be subjugated. In view of this understanding of gratitude, $\mathrm{Li}[49$, $52,53]$ developed a mechanism for gratitude development in children, morality of justice.

\section{Morality of Justice}

Morality of justice encompasses three interrelated and integral dimensions of the mechanism for gratitude development in children: parental love, induction (moral reasoning) and discipline. First, parental love is the most critical quality for parents, and is the prerequisite and starting point in the development of a strong parent-child relationship. Parental love serves as the seed for children's love and other positive emotions such as caring, empathy, compassion, generosity, and even trust [50, 54-57]. According to the attachment theory [58-67], attaining or maintaining proximity to a caring mother figure is critically important for children and neglectful parenting has serious ill-effects on a child's personality development and aspects of mental health, such as depression. Parental love has also been found to be strongly related to a prosocial disposition [68]. In sum, parental love plays an essential role in the development of gratitude in children and of an affective bond between parents and children.

Induction, which is also termed moral reasoning, helps children better understand parental love theoretically. Social justice theory lies at the core of the theoretical framework for induction. According to the social justice theory [69-76], moral development is primarily based on social justice achieved through balancing different rights, obligations, and benefits. Social justice functions as the bedrock of social cooperation and harmony. Given the fact that the hedonistic predispositions of human beings are largely inherent $[46,73$, 77], Piaget [74] and Kohlberg [72, 78] concluded that one's moral development is not automatic, simply occurring in tandem with chronological aging. This suggests that children will not appreciate rights and benefits arising from parental love until they come to understand the concept of obligation. Lack of knowledge about social justice could be the reason that some children take parental love for granted or even think parents owe them, which occurred with some children of Chinese one-child generations. Thus, social justice theory provides a vital avenue for subjugating one's hedonistic needs theoretically [71]. Through balancing diverse rights, obligations and benefits, children can learn to respect mutual rights and benefits, and then develop a quality of gratitude in their personality.

Last but not least, it is discipline that can eventually transform induction or moral reasoning into moral acts according to the internalisation theory [71, 79-82]. Kohlberg [78] pointed out that moral reasoning does not lead naturally to moral acts. Indeed, thinking and doing are two different things. Given moral development is seen as a painful process as it is in opposition to the hedonistic or selfish nature of human beings [46], the development of gratitude in children towards parents is predestined to be a demanding 
undertaking as it may involve high costs [31, 83]. Therefore, Hoffman [71] stated that only discipline can exert constraint on the self-interest tendency of a child and it can, as explained by Blustein, "gradually shift from its position of outward authority to an inner position of self-control" [36].

These three dimensions of morality of justice are the integral parts of the mechanism for gratitude development in children. Parental love is the premise and source of the reciprocity of children's love. Induction provides a theoretical basis for children to soundly understand rights, benefits, and more importantly, associated obligations, arising from parental love. Discipline then internalises this theoretical understanding into behavioural habits. These three dimensions are interrelated and indispensable. To determine which of the three dimensions plays a larger role in gratitude development, in 2015, Li [84] conducted an empirical study that investigated 589 high school students aged from 11 to 16 on the correlation between their parental practice and their grateful acts. The analysis of Pearson correlation, partial correlation and multiple regression revealed that discipline plays a role twice as important as parental love and induction. This finding suggests the greater importance that discipline has in making grateful children and developing a strong parent-child relationship. This also suggests that lack of parental discipline may be the crux of a widespread lack of gratitude in spoilt Chinese one-child generations. What then are parental disciplinary measures?

Parental discipline encompasses two measures, curbing desires and punishment for breaching rules agreed upon through induction or moral reasoning between parents and children $[49,53]$. Curbing desires is to keep benefits and rights that children enjoy in the family appropriate to their age and their family situations. For example, it might not be appropriate to buy an iPhone 6 for a seventh-grader for a middle-income family. It might be a good idea to consider what children need, instead of what they want. Punishment for undesirable behaviour is a good means to develop in children a sense of responsibility for their own behaviour. According to Skinner's operant conditioning theory [85], punishment is a core tool for shaping behaviour and includes positive punishment (verbally, such as reprimanding, or physically, such as spanking) and negative punishment (or penalty, such as the removal of a favourite toy following undesirable behaviour). However, curbing desires, and punishment for undesirable behaviour are both of a negative nature and occur in an unanticipated and irregular manner. They might not achieve the desired educational effect if parents do not have a good sense of social justice and moral reasoning skills, and if parents discipline children inconsistently and intermittently. This negative effect is also more likely to occur when parents are constantly under various kinds and levels of work and life stress. Besides the requirement for high-level parental quality, two other issues are also identified in these two parental disciplinary measures for gratitude development in children. The first is that one of the three integral parts of social justice, obligation, is missing; the second is the lack of an active and regular measure to internalise social justice in children's behavioural habits. Are chores able to do something about these two deficiencies?

\section{Chores}

When you read the word chores, the thoughts or feelings it evokes could be of hardship, struggle, solitude, or, more generally, of an unpleasant experience. Yes, unlike cooking the occasional meal, which can be fun or a relief after a long day of mental work, chores suggest hardship and tedium. First of all, chores are laborious. It takes effort to mow and trim the lawn, make a big meal or hand-wash a large accumulation of dirty dishes. Second, chores are daily household tasks that are destined to be tedious and boring. Imagine how you would feel should you have to rack your brains to compile menus for three meals a day that are different from the meals of yesterday and the day before and having only a few common options of vegetables and meat. And then there is the thought of the preparation and cleaning up - washing, peeling, chopping, cooking, plating, dishwashing, and all this day in day out. Yes, chores mean hardship and tedium.

However, it is such hardship and tedium that brings about two competing views about the role of chores, revealed in the literature review. Most of scholars were amazed and excited about the benefits they found arising from engaging children in chores. These benefits included enhancing interpersonal skills, responsibility [27, 86-88], educational attainment and career success $[89,90]$, and mental health, such as empathy [e.g. 91, 92]. However, a few researchers [e.g. 93] pointed out some negative perceptions that surround chores in family relationships, such as their being a source of conflict between husband and wife, and between parents and adolescents, and a source of mental labour and stress. How could the hardship and tedium of chores bring about two such contrasting effects, such as improving interpersonal skills and harming family bonds?

Li [34] explored the mechanism of how chores play a role in a parent-child relationship, which might lay the foundation for other relationships within and beyond the family in childhood and well into adulthood. As discussed above, to develop a strong parent-child relationship, parental love alone is not sufficient. To transform parental love into the reciprocity of children's love, induction or moral reasoning and discipline are also required in parenting. Induction aims to enhance the understanding of social justice theoretically, and parental discipline is to internalise such induction into behavioural habits. However, there exist the two issues of lack of obligation and lack of an active and regular discipline measure in parental discipline. Chores provide an ideal vehicle to make up for these deficiencies. Chores are family obligations that require every family member to contribute and to endure the hardship and tedium associated with the tasks so that the household can run efficiently. And chores are household tasks that have to be 
undertaken every day. This means that children can be actively disciplined by their parents to engage in routine chores from an early age until doing chores becomes a habit. Through engaging in routine chores, children will be able to learn that their rights should be earned by correspondingly fulfilling their obligations, and that there are no rights in the world without obligations attached to them. "Morality is embedded in and is an outcome of everyday family practices" [94], which plays the role of "sobering children into the social fact that growing up means that obligation precedes pleasure" [94]. For the development of a habitus of justice, childhood is a vital phase [46]. Engaging in routine chores throughout childhood provides a great means for parents to internalise or habitualise a sense of social justice in their children's inner states, which helps transform parental love into the reciprocity of children's love, and a strong bond between parents and children can then be forged.

Chores, as the major integral part of child development for a sense of obligation, are sadly missing in our modern society. Kornrath [5] attributed self-centredness in young people to changes in parenting styles in the 1980 's, when parents shifted their focus to success and competition, and children started to be perceived as an emotional asset and became the object of being loved only $[95,96]$. In addition, growing technological advances such as washing machines and dish washers, as well as much improved aged-care welfare systems also enabled parents not to need much help from their children to run the household or make for a living. As a result, few children were required to spend time in helping around the house, not only in China [41-45] but also in the West in countries such as the United States of America $[92,93,97]$. Thus, chores as a great opportunity of engaging children in family obligation to develop their sense of social justice have been largely neglected.

However, albeit with the significant role of chores in child development, to engage children in chores will not necessary lead to a strong parent-child relationship, because this also requires parental love, a sense of social justice and authority. First, parents need to love their children; otherwise children will perceive themselves as cheap labour. Second, parents must have a good sense of social justice, as their children must feel they are being treated justly and fairly. Third, parents need to have the authority to engage children in chores consistently. A lack of any of the above prerequisites could mean that chores become a source of conflict between parents and children, and this may extend to their adult life and become a source of conflict for other family relations, such as conflict between a husband and wife.

Nevertheless, the advantages of engaging children in routine chores are remarkable when compared to other disciplinary strategies such as physical punishment for undesired behaviour. Besides the two advantages of engaging obligation in social justice practice and being an active and regular measure, a third advantage of chores is also of significance, which is that parents do not need to have moral reasoning skills as long as they have a good sense of social justice. This could explain why some children of parents with low educational backgrounds might still be very grateful to their parents [26]. However, despite all the advantages, people need to be aware that when assigning chores individual difference in psychological traits, such as intelligence and personality, should be taken into consideration; and excessive housework may impede a child's academic performance [90].

\section{Conclusions}

To develop a strong bond between parents and children, parental love alone is not sufficient. Induction (moral reasoning) and discipline are required to help children to understand social justice and internalise it so that it becomes standard behaviour. Discipline plays a more important role than the other two factors in gratitude development in children, and in this area chores may function as an active and constant disciplinary measure and play a unique role in developing gratitude towards parents in children and a strong bond between parents and children. Therefore, theoretically chores could be an incubator for a strong parent-child relationship.

Although this theoretical discussion gives a logical reason for the CLHLS finding that sons-in-law performed better affective care to their parents-in-law under the influence of their wives (the daughters) than daughters-in-law, more empirical studies are surely needed to verify that it is more routine chores than gender that makes a strong parent-child bond. It would be more convincing if we can empirically prove that adult sons who did routine chores in their childhood have a stronger bond with their old parents than those sons and even daughters who did not.

\section{REFERENCES}

[1] Salt B. Time for the me generation to accept hardship.(PrimeSpace). The Australian. 2016.

[2] Squires W. Is this the most narcissistic generation we've ever seen? The Sydney Morning Herald. 2013 April 20.

[3] Stein J. Millennials: The Me Me Me Generation. Time. 2013 May 20.

[4] Twenge JM. Generation me: Why today's young Americans are More confident, assertive, entitled--and more miserable than ever before. New York: Free Press; 2006.

[5] Williams R. Is the "Me Generation" less empathetic? Psychology Today. 201016 June.

[6] Baudrillard J. Simulations. New York: Semiotext; 1983.

[7] Johnson SD. Will our research hold up under scrutiny? Journal of Industrial Teacher Education. 1995;32(3):4.

[8] Turner B. Theories of Modernity and Postmodernity. London: Sage; 1990. 
[9] Fong M. One child: The story of China's most radical experiment. Boston, MA: Houghton Mifflin Harcourt 2016.

[10] Johnson KA. China's hidden children: Abandonment, adoption, and the human costs of the One-Child Policy. Chicago, IL: University of Chicago Press; 2016.

[11] Short SE, Zhai F, Xu S, Yang M. China's one-child policy and the care of children: An analysis of qualitative and quantitative data. Social Forces. 2001;79(3):913-43.

[12] McCready A. The me, me, me epidemic: A step-by-step guide to raising capable, grateful kids in an over-entitled world. New York: Penguin Publishing Group; 2015.

[13] Twenge JM, Campbell WK. The narcissism epidemic: Living in the age of entitlement: Atria Books; 2009.

[14] Millward C. Caring for elderly parents. Family Matters (Australian Institute of Family Studies). 1999;52:26-30.

[15] de Vaus D. Adult-parent relationships. Family Matters (Australian Institute of Family Studies). 1995;41:22-9.

[16] Millward C. Intergenerational family support. Family Matters (Australian Institute of Family Studies). 1994;39:10-3.

[17] Chen S. Aging with Chinese characteristics: A public policy perspective. Ageing International. 2009(34):172-88.

[18] Zimmer Z, Kwong J. Socioeconomic status and health among older adults in rural and urban China. Journal of Aging and Health. 2004(16):44-70.

[19] Li S. The moral dilemma and social disadvantages of placing unique emphasis on the filial child. The International Journal of Critical Cultural Studies. 2013;11(1):1-10.

[20] Emmons RA. The psychology of gratitude: An introduction. In: Emmons RA, McCullough ME, editors. The psychology of gratitude. Oxford: Oxford University Press; 2004. p. 3-16.

[21] Emmons RA, Shelton CM. Gratitude and the science of positive psychology. Handbook of positive psychology. 2002;18:459-71.

[22] Fredrickson BL. Gratitude, like other positive emotions. In: Emmons RA, McCullough ME, editors. The psychology of gratitude. Oxford: Oxford University Press; 2004. p. 145-66.

[23] Watkins PC. Gratitude and subjective well-being. In: Emmons RA, McCullough ME, editors. The psychology of gratitude. Oxford: Oxford University Press; 2004. p. 167-92.

[24] Zeng Y. Beijing University Professor Zeng Yi: Better return for peasants at an old age from raising a daughter than a son. Beijig: National Development Research Institute of Beijing University; 2015 [cited 2015 26/11]; Available from: http://comments.caijing.com.cn/20151123/4016274.shtml.

[25] Ho DYF. Relational orientation in Asian social psychology. In: Kim U, Berry JW, editors. Indigenous psychologies: Research and experience in cultural context. Thousand Oaks, CA: Sage; 1993.

[26] Seymour S. Expressions of responsibility among Indian children: Some precursors of adult status and sex roles. Ethos. 1988;16(4):355-70.

[27] White LK, Brinkerhoff DB. Children's work in the family: Its significance and meaning. Journal of Marriage and the Family. 1981;43(4):789-98.
[28] Yeh KH. The Dual Filial Piety Model in Chinese culture: Retrospect and prospects [Huaren Xiaodao Shuangyuan Moxing Yanjiu de Huigu yu Qianzhan]. Indigenous Psychological Research in Chinese Societies. 2009(32):101-48.

[29] Yeh KH, Cheng SP, editors. Parenting, children's empathy and compliance, and filial types. 113th Annual Convention of the American Psychological Association (APA); 2005; Washington D.C., USA.

[30] Yeh KH, Yi CC, Tsao WC, Wan PS. Filial piety in contemporary Chinese societies: A comparative study of Taiwan, Hong Kong, and China. International Sociology. 2013;28(3):277-96.

[31] Li S. "All good is of parents" and its Chinese context. China Report. 2014;50(4):1-12.

[32] Das Gupta M, Zhenghua J, Bohua L, Zhenming X, Chung W, Hwa-Ok B. Why is Son preference so persistent in East and South Asia? a cross-country study of China, India and the Republic of Korea. The Journal of Development Studies. 2003;40(2):153-87.

[33] Higgins LT, Zheng M, Liu Y, Sun CH. Attitudes to Marriage and Sexual Behaviors: A Survey of Gender and Culture Differences in China and United Kingdom. Sex Roles. 2002;46(3):75-89.

[34] Li S. Household chores in gratitude development in children. In: Howard AR, editor. Psychology of gratitude: New research. Hauppauge, NY: Nova Science; 2016. p. 45-60.

[35] Keller S. Four theories of filial duty. The Phlosophical Quarterly. 2006;56(223):254-75.

[36] Blustein J. Parents and children: The ethics of the family. New York, NY: Oxford University Press; 1982.

[37] English J. What do grown children owe their parents? In: Jecker NS, editor. Aging And Ethics. Totowa, NJ: Humana Press; 1992. p. 147-54.

[38] Nicholas D. The friendship model of filial obligations. Journal of Applied Philosophy. 1995;12(1):77-87.

[39] Lamborn SD, Mounts NS, Steinberg L, Dornbusch SM. Patterns of competence and adjustment among adolescents from authoritative, authoritarian, indulgent, and neglectful families. Child Development. 1991;62(5):1049-65.

[40] Maccoby EE, Martin JA, Hetheringon E. Handbook of child psychology. New York: Wiley; 1983. 1 p.

[41] Lu T. Survey on gratitude in junior middle school students in rural areas and measures of school's gratitude education (Nongcun Chuzhongsheng Ganen Xianzhuan Diaocha yu Xuexiao Shishi Ganen Jiaoyu Celue Yanjiu) China's Collective Economy. 2009(12):190-1

[42] Li M, Peng B. Survey on gratitude in middle school students, measures and suggestions for gratitude education (Zhongxuesheng Ganen Xianzhuang Diaocha yu Shishi Ganen Jiaoyu Duice yu Jianyi). Basic Education Review. 2011(13): 67-9.

[43] Chen Y, Yang D. Investigation of gratitude in middle school students from a high school in Tangshan city (Zhongxuesheng Ganen Guannian Xianzhuang de Diaocha yu Yanjiu -- yi Tangshan Shiqu Gaozhongsheng Weili). 
Adolescents' Invention and Creation. 2011(3):44-5.

[44] Ma X. Survey on gratitude in teacher students (Dui Gaoshi Xuesheng Ganen Xianzhuang de Diaocha Yanjiu). Journal of Chongqing University of Science and Technology(Social Sciences Edition) 2011(1):200-4.

[45] Zhang C. Survey on gratitude to parents in university students -- Sampling Beijing Forestry University students (Dangdai Daxuesheng dui Fumu Ganen Xianzhuang de Diaocha Yanjiu -- Yi Linye Daxuesheng Weili). Theory Research. 2013(22):116-8.

[46] Aristotle. The ethics of Aristotle: The Nicomachean ethics. Harmondsworth, New York: Penguin; trans. 1976. 383 p.

[47] Williams B. Ethics and the limits of philosophy. London: Fontana; 1985.

[48] Robert RC. The blessings of gratitude. In: Emmons RA, McCullough ME, editors. The psychology of gratitude. Oxford: Oxford University Press; 2004. p. v-xi.

[49] Li S. How to make a grateful child: Reflection on gratitude campaigns in China in recent years. Sage Open. 2014;4(4):1-7.

[50] Komter AE. Gratitude and gift exchange. In: Emmons RA, McCullough ME, editors. The psychology of gratitude. Oxford: Oxford University Press; 2004. p. 195-212.

[51] Froh J, Bono G. Making grateful kids: The science of building character. Wst Conshohocken, PA: Templeton Press 2014.

[52] Li S. Chinese Parents' Role Modeling: Promoting Gratitude. Childhood Education. 2015;91(3):190-7.

[53] Li S. A mechanism for gratitude development in a child. Early Child Development and Care (Routledge). 2016;in press.

[54] Fredrickson BL. What good are positive emotions? Review of General Psychology. 1998;2(3):300-19.

[55] McNeely CA, Barber BK. How do parents make adolescents feel loved? Perspectives on supportive parenting from adolescents in 12 cultures. Journal of Adolescent Research. 2010;25(4):601-31

[56] Fredrickson BL. Positive emotions broaden and build. Advances in Experimental Social Psychology. 2013;47(Journal Article):1-53.

[57] Fredrickson BL. The broaden-and-build theory of positive emotions. Philosophical Transactions of the Royal Society of London Series B: Biological Sciences. 2004;359(1449):1367-77.

[58] Bowlby J. Attachment and loss. New York: Basic Books; 1980.

[59] Bowlby J. Attachment and loss: retrospect and prospect. American Journal of Orthopsychiatry. 1982;52(4):664-78.

[60] Bowlby J. Attachment and loss. New York: Basic Books; 1969.

[61] Brenning K, Soenens B, Braet C, Bal S. The role of parenting and mother-adolescent attachment in the intergenerational similarity of internalizing symptoms. Journal of Youth and Adolescence. 2012;41(6):802-16.

[62] Ainsworth M. Object relations, dependency, and attachment:
A theoretical review of the infant-mother relationship. Child Development. 1969(40):969-1025.

[63] Ainsworth M. The effects of maternal deprivation: A review of findings and controversy in the context of research strategy. Public Health Papers. 1961(14):97-165.

[64] Ainsworth M. Infancy in Uganda: Infant care and the growth of love. Baltimore: Johns Hopkins Press; 1967.

[65] Ainsworth M. Attachments beyond infancy. American Psychologist. 1989;44(4):709-16.

[66] Bowlby J. Child care and the growth of love. Harmondsworth, England: Penguin Books; 1965.

[67] Steele H, Steele M. Parenting matters: An attachment perspective. In: Mcclain L, Daniel C, editors. What is parenthood?: Contemporary debates about the family. New York and London: New York University Press; 2013. p. 214-33.

[68] Honig AS. How teachers and caregivers can help young children become more prosocial. In: Chesebrough E, King P, Gullotta T, Bloom M, editors. A blueprint for the promotion of prosocial behavior in early childhood. New York: Kluwer Academic/Plenum Publishers; 2004. p. 51-91.

[69] Deigh J. Love, guilt, and the sense of justice. Inquiry. 1982;25(4):391-416.

[70] Elm DR, Weber J. Measuring moral judgment: The moral judgment interview or the defining issues test? Journal of Business Ethics. 1994;13(5):341-55.

[71] Hoffman ML. Moral internalization, parental power, and the nature of parent-child interaction. Developmental Psychology. 1975;11(2):228-39.

[72] Kohlberg L. The psychology of moral development: The nature and validity of moral stages. San Francisco, CA: Harper \& Row; 1984.

[73] Hume D. A treatise of human nature. New York, NY: Dent; 1960.

[74] Piaget J. The moral judgment of the child. New York: Free Press; $1965.410 \mathrm{p}$.

[75] Rawls J. A theory of justice. Oxford: Oxford University Press; 1999.

[76] Rest JR. Development in judging moral issues. Minneapolis: University of Minnesota Press; 1979.

[77] Kohlberg L. Development of moral character and moral ideology. In: Hoffman LW, Hoffman ML, editors. Review of child development research. New York, NY: Russell Sage Foundation; 1964. p. 383-432.

[78] Kohlberg L. Moral stages and moralization: The cognitive-developmental approach In: Lickona $\mathrm{T}$, editor. Moral Development and Behavior: Theory, Research and Social Issues. Holt, NY: Rinehart and Winston.; 1976. p. 31-53.

[79] Minton C, Kagan J, Levine JA. Maternal control and obedience in the two-year-old. Child Development. 1971;42(6):1873-94.

[80] Schoggen P. Enivronmental forces in the everyday lives of children. In: Barker RG, editor. The stream of behavior: 
Explorations of its structure \& content. East Norwalk, CT: Appleton-Century-Crofts; 1963. p. 42-69.

[81] Simmons H, Schoggen P. Mothers and fathers as sources of environmental pressure on children. In: Barker RG, editor. The stream of behavior: Explorations of its structure \& content. East Norwalk, CT: Appleton-Century-Crofts; 1963. p. 70-7.

[82] Hoffman ML. Power assertion by the parent and its impact on the child. Child Development. 1960;31(1):129-43.

[83] Bee HL. Lifespan development. New York, NY: HarperCollins College Publishers; 1994.

[84] Li S. Testing scales of parenting practice and filial acts in children and exploring their correlations. In: Howard AR, editor. Psychology of gratitude: New research. Hauppauge, NY: Nova Science; 2016. p. 21-44.

[85] Skinner BF. The behavior of organisms: An experimental analysis. New York: Appleton-Century-Crofts; 1938.

[86] Rogoff B. The cultural nature of human development. Oxford: Oxford University Press; 2003.

[87] Whiting BB, Whiting JWM, Longabaugh R. Children of six cultures: a psycho-cultural analysis. Cambridge, MA: Harvard University Press; 1975. 237 p.

[88] Wingard L. Mentioning homework first in parent-child interactions. Talk and Text. 2006(26):573-98.

[89] Wilcox KC. The importance of civic responsibility in higher performing middle schools: An empirical study. Education and Urban Society. 2011;43(1):26-41.

[90] Smith C. The origin and expression of achievement-related motives in children. In: Smith CP, editor. Achievement-related Motives in Children. New York, NY: Russell Sage Foundation; 1969. p. 102-50.

[91] Grusec JE, Goodnow JJ, Cohen L. Household work and the development of concern for others. Developmental Psychology. 1996;32(6):999-1007.

[92] Rende R, Prosek J. Raising can-do kids: Giving children the tools to thrive in a fast-changing world. Perigee: Penguin; 2015.

[93] Rende R. The developmental significance of chores: Then and now. Brown University Child and Adolescent Behavior Letter. 2015;31(1):1-7.

[94] Ochs E, Kremer-Sadlik T. Introduction: Morality as family practice. Discourse \& Society. 2007;18(1):5-10.

[95] Cunningham H. Children and childhood in western society since 1500. 2nd ed. New York, NY: Pearson Longman; 2005. $238 \mathrm{p}$.

[96] Zelizer VA. Pricing the priceless child. Princeton, NJ: Princeton University Press; 1994. 296 p.

[97] Klein W, Graesch AP, Izquierdo C. Childen and chores: A mised-methods study of children's household work in Los Angeles families. Anthropology of Work Review. 2009; XXX(3):98-109. 